\title{
Contribution of sulfuric acid and oxidized organic compounds to particle formation and growth
}

\author{
F. Riccobono ${ }^{1}$, L. Rondo ${ }^{2}$, M. Sipilä ${ }^{3}$, P. Barmet ${ }^{1}$, J. Curtius ${ }^{2}$, J. Dommen ${ }^{1}$, M. Ehn ${ }^{3}$, S. Ehrhart ${ }^{2}$, M. Kulmala ${ }^{3}$, \\ A. Kürten ${ }^{2}$, J. Mikkilä ${ }^{3}$, P. Paasonen ${ }^{3}$, T. Petäjä ${ }^{3}$, E. Weingartner ${ }^{1}$, and U. Baltensperger ${ }^{1}$ \\ ${ }^{1}$ Laboratory of Atmospheric Chemistry, Paul Scherrer Institute, Switzerland \\ ${ }^{2}$ Institute for Atmospheric and Environmental Sciences, Goethe-University Frankfurt am Main, Germany \\ ${ }^{3}$ Department of Physics, University of Helsinki, Finland
}

Correspondence to: U. Baltensperger (urs.baltensperger@psi.ch)

Received: 6 April 2012 - Published in Atmos. Chem. Phys. Discuss.: 3 May 2012

Revised: 27 September 2012 - Accepted: 28 September 2012 - Published: 19 October 2012

\begin{abstract}
Lack of knowledge about the mechanisms underlying new particle formation and their subsequent growth is one of the main causes for the large uncertainty in estimating the radiative forcing of atmospheric aerosols in global models. We performed chamber experiments designed to study the contributions of sulfuric acid and organic vapors to the formation and early growth of nucleated particles. Distinct experiments in the presence of two different organic precursors (1,3,5-trimethylbenzene and $\alpha$-pinene) showed the ability of these compounds to reproduce the formation rates observed in the low troposphere. These results were obtained measuring the sulfuric acid concentrations with two chemical ionization mass spectrometers confirming the results of a previous study which modeled the sulfuric acid concentrations in presence of 1,3,5-trimethylbenzene.

New analysis methods were applied to the data collected with a condensation particle counter battery and a scanning mobility particle sizer, allowing the assessment of the size resolved growth rates of freshly nucleated particles. The effect of organic vapors on particle growth was investigated by means of the growth rate enhancement factor $(\Gamma)$, defined as the ratio between the measured growth rate in the presence of $\alpha$-pinene and the kinetically limited growth rate of the sulfuric acid and water system. The observed $\Gamma$ values indicate that the growth is already dominated by organic compounds at particle diameters of $2 \mathrm{~nm}$. Both the absolute growth rates and $\Gamma$ showed a strong dependence on particle size, supporting the nano-Köhler theory. Moreover, the separation of the contributions from sulfuric acid and organic compounds to particle growth reveals that the organic contribution seems to
\end{abstract}

be enhanced by the sulfuric acid concentration. Finally, the size resolved growth analysis indicates that both condensation of oxidized organic compounds and reactive uptake contribute to particle growth.

\section{Introduction}

Aerosols affect the climate by directly absorbing or scattering the solar radiation. Particles with diameters larger than $\sim 50-100 \mathrm{~nm}$ (the exact diameter depends on water supersaturation and particle chemical composition) can act as cloud condensation nuclei (CCN) (Köhler, 1936; McFiggans et al., 2006) and influence cloud lifetime and optical properties (Twomey, 1977; Albrecht, 1989; Seinfeld and Pandis, 2006). Aerosol particles can either be directly emitted (primary emissions) or be formed in the atmosphere by nucleation of gaseous precursors (secondary formation). Global models suggest that up to $45 \%$ of global low-level cloud $\mathrm{CCN}$ may originate from secondary formation (Merikanto et al., 2009). However, the lack of knowledge about the mechanism underlying aerosol nucleation is one of the causes for the large uncertainty in estimation of the radiative forcing of atmospheric aerosols to predict the climate (IPCC, 2007).

At a given nucleation rate (i.e., number of particles created per unit of volume and time) the number of particles that can grow to $\mathrm{CCN}$ sizes depends on the competition between the growth rate and the coagulation of the new particles onto the pre-existing ones (Kerminen and Kulmala, 2002). The efficiency of coagulation scavenging by large particles 
is greatest when the nucleated particles are small (diameter $D_{\mathrm{p}}<10 \mathrm{~nm}$ ) due to their large diffusion coefficient. Therefore, initial growth rates are a key issue in determining which fraction of freshly nucleated particles becomes large enough to act as CCN (Kerminen et al., 2001).

Hydrated sulfuric acid is considered to be the main vapor responsible for nucleation under atmospheric conditions (Weber et al., 1996; Kulmala et al., 2004a; Curtius, 2006; Kulmala and Kerminen, 2008; Sipilä et al., 2010). Besides sulfuric acid, other compounds such as ammonia and organics are thought to participate in atmospheric nucleation. Recently published results show evidence of nitrogen containing molecules (e.g., ammonia and amines) in nucleating clusters (Berndt et al., 2010; Petäjä et al., 2011; Kirkby et al., 2011). Aminium salts were also observed in the $8-20 \mathrm{~nm}$ particle size range during field measurements (Smith et al., 2010). A number of laboratory and field studies report direct and/or indirect observations indicating that organic compounds contribute significantly to the chemical composition of freshly nucleated particles (O'Dowd et al., 2002; Wehner et al., 2005; Smith et al., 2008; Zhang et al., 2009; Metzger et al., 2010; Paasonen et al., 2009, 2010; Kuang et al., 2012; Pierce et al., 2011, 2012; Riipinen et al., 2011). Current global models include both sulfuric acid and oxidation products of organic vapors (i.e., monoterpenes) in the aerosol growth process (Spracklen et al., 2008; Pierce and Adams, 2009). However, constraining the model uncertainties requires a better understanding of the roles these vapors play in the nucleation and growth mechanisms (Riipinen et al., 2011).

In this work we present the results from a set of chamber experiments designed to study the contribution of sulfuric acid and organic vapors to the formation and to the early growth of nucleated particles. First we performed three nucleation experiments in the presence of 1,3,5trimethylbenzene (TMB), an anthropogenic organic aerosol precursor. The aim of the TMB experiments was the confirmation of the results of our previous nucleation experiments (Metzger et al., 2010). These showed that nucleation experiments performed under the presence of sulfuric acid and TMB in the Paul Scherrer Institute (PSI) environmental chamber (Metzger et al., 2010) reproduced the particle formation rates observed in the atmosphere at similar sulfuric acid concentrations. In that work, considerable uncertainty arose from using a model to determine the sulfuric acid concentrations. The $\mathrm{H}_{2} \mathrm{SO}_{4}$ concentration was calculated with a simple kinetic model which used the TMB lifetime to retrieve the concentration of $\mathrm{OH}$ radicals needed to oxidize the $\mathrm{SO}_{2}$ molecules. Wall losses and condensation on aerosol particles were taken into account as well. In the present study we reduced this uncertainty by measuring the sulfuric acid concentration with two independently calibrated chemical ionization mass spectrometers (Eisele and Tanner, 1993; Petäjä et al., 2009; Kürten et al., 2012).
Furthermore we performed a second set of experiments using $\alpha$-pinene, a common biogenic organic precursor. We investigated the role of the oxidation products of $\alpha$-pinene in the growth process of nanoparticles through eight photooxidation experiments. We measured the size dependent growth rates under various vapor concentrations using four condensation particle counters (CPC battery) and a scanning mobility particle sizer (SMPS). We will discuss different growth rate analysis methods and their limitations. Finally, the observed size dependent growth rates will be compared with the modeled growth rates expected by the measured sulfuric acid concentration, obtaining the size dependent organic contribution to particle growth.

\section{Methods}

We investigated the particle formation rates and the subsequent growth rates (GR) during 11 photooxidation experiments in the $27-\mathrm{m}^{3}$ PSI environmental chamber in the presence of $\mathrm{NO}_{\mathrm{x}}$ and $\mathrm{SO}_{2}$ at various mixing ratios and two different organic precursors: 1,3,5-trimethylbenzene (TMB) and $\alpha$-pinene. As light source four $4 \mathrm{~kW}$ xenon arc lamps were used, which closely simulate the sun light spectrum (Paulsen et al., 2005).

In the beginning of an experiment the chamber was filled with purified and filtered air in the dark (i.e., lights off). After the addition of the various trace gases $\mathrm{H}_{2} \mathrm{O}, \mathrm{SO}_{2}, \mathrm{NO}_{\mathrm{x}}$, the organic precursor was injected through a vaporizer. When the concentrations of the gases were stable the experiment was started by turning on the lights and monitoring the gas and the aerosol phase evolution.

The PSI environmental chamber includes the following instrumentation: humidity sensor (Rotronic Hygro Clip SC05), $\mathrm{SO}_{2}$ monitor (Enhanced Trace Level $\mathrm{SO}_{2}$ Analyzer, Model 43i-TLE, Thermo Scientific, USA), trace level $\mathrm{NO}_{\mathrm{x}}$ analyzer (Thermo Environmental Instruments $42 \mathrm{C}$ ), $\mathrm{O}_{3}$ monitor (Monitor Labs Inc. Model 8810), proton transfer reaction mass spectrometer (PTR-MS, Ionicon) to measure the organic vapors, and a scanning mobility particle sizer (SMPS, particle diameter size range $14-800 \mathrm{~nm}$ ) (Wang and Flagan, 1990). A second SMPS with a differential mobility analyzer (DMA) designed to have a higher size resolution and transmission for particle diameters between 5 and $60 \mathrm{~nm}$ was also used. A CPC battery, composed of three TSI CPCs, a model TSI 3776 with a $50 \%$ counting efficiency diameter $D_{50}$ of $3.2 \mathrm{~nm}$, a TSI 3772 with $D_{50}=5.6 \mathrm{~nm}$ and a TSI 3010 with $D_{50}=10.5 \mathrm{~nm}$ and, a Particle Size Magnifier (PSM, Airmodus A09 prototype) with $D_{50}=1.5 \mathrm{~nm}$ (Vanhanen et al., 2011), served to determine the initial particle growth rates. Finally two chemical ionization mass spectrometers (CIMS) measured the sulfuric acid concentration. The two CIMS were constructed following the previous work of Eisele and Tanner (Eisele and Tanner, 1993; Berresheim et al., 2000; Mauldin et al., 2001; Petäjä et al., 2009). All the experiments 
Table 1. Initial gas mixing ratios for $3 \mathrm{TMB}$ and $8 \alpha$-pinene experiments.

\begin{tabular}{lrrrr}
\hline Exp No. & $\begin{array}{r}{[\mathrm{VOC}]} \\
(\mathrm{ppbv})\end{array}$ & $\begin{array}{r}{\left[\mathrm{SO}_{2}\right]} \\
(\mathrm{ppbv})\end{array}$ & $\begin{array}{r}{[\mathrm{NO}]} \\
(\mathrm{ppbv})\end{array}$ & $\begin{array}{r}{\left[\mathrm{NO}_{2}\right]} \\
(\mathrm{ppbv})\end{array}$ \\
\hline TMB 1 & 250 & 5 & 93 & 64 \\
TMB 2 & 250 & 1 & 76 & 61 \\
TMB 3 & 250 & 0.2 & 72 & 62 \\
$\alpha$-p 1 & 46 & 0 & 20 & 15 \\
$\alpha$-p 2 & 260 & 0 & 100 & 200 \\
$\alpha$-p 3 & 31 & 5 & 13 & 10 \\
$\alpha$-p 4 & 25 & 5 & 10 & 12 \\
$\alpha$-p 5 & 30 & 0 & 12 & 12 \\
$\alpha$-p 6 & 13 & 0 & 4 & 15 \\
$\alpha-\mathrm{p} \mathrm{7}$ & 99 & 0 & 100 & 300 \\
$\alpha-\mathrm{p} \mathrm{8}$ & 92 & 0 & 8 & 30 \\
\hline
\end{tabular}

were performed at $50 \% \mathrm{RH}( \pm 5 \%)$ and $20^{\circ} \mathrm{C}\left( \pm 2{ }^{\circ} \mathrm{C}\right)$. Typical initial concentrations of gases varied between 4 and 200 ppbv for $\mathrm{NO}_{\mathrm{x}}, 0$ and 5 ppbv of $\mathrm{SO}_{2}$, and 13 and $260 \mathrm{ppbv}$ of VOC (Table 1).

\subsection{Determination of particle formation rates and growth rates}

\subsubsection{Particle formation rates}

Particle formation rates at $D_{\mathrm{p}}=1.5 \mathrm{~nm}$ were retrieved from the formation rate $(\mathrm{d} N / \mathrm{d} t)$ measured by the PSM and by the TSI 3776 CPC. In the first step the measured particle concentrations were corrected for diffusion losses occurring in the sampling line assuming laminar flow diffusion losses in straight tubes (equation 8.56 in Baron and Willeke, 2001). This assumption is justified by the absence of pipe elbows and bends with small radius of curvature $(<10 \mathrm{~cm})$ in the sampling lines. The apparent measured formation rates $\mathrm{d} N / \mathrm{d} t$ were then corrected for coagulation and wall losses following the same procedure as described by Metzger et al. (2010).

\subsubsection{Growth rates from the CPC battery measurements}

Particle growth rates were determined from the CPC battery and the SMPS measurements. The CPC battery allowed determining the initial growth rates for particle diameters between 1.5 and $6 \mathrm{~nm}$. Before the start of a nucleation experiment, when the lights were still off, the particle concentration in the environmental chamber was close to zero (the background concentration was in the order of $10 \mathrm{~cm}^{-3}$ ). When the lights are turned on, the oxidation of $\mathrm{SO}_{2}$ and the organic precursors generates nucleating and condensing vapors (e.g., sulfuric acid and oxidized organic molecules) and that produces stable clusters that grow to detectable sizes by coag-

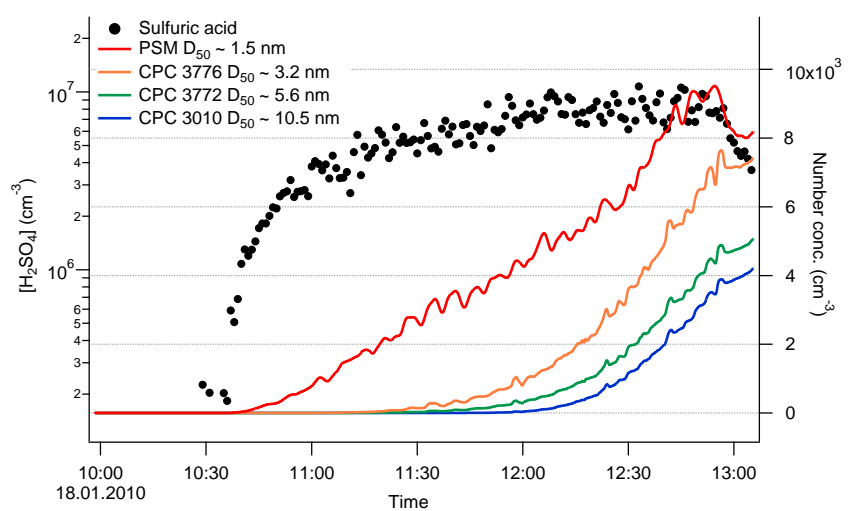

Fig. 1. Example of the time evolution of sulfuric acid concentration (left axis), particle concentration measured by PSM and CPCs (right axis) during $\alpha$-p 6 experiment.

ulation and condensation. The corresponding condensational growth rate depends on the availability of condensing vapors.

Growing particles appear in a CPC as soon as they exceed the minimum detectable size of that specific CPC. The analysis of the time delay between the CPC signals, together with the accurate determination of the detection thresholds of the CPCs allowed us to retrieve the growth rates of the particles with $D_{\mathrm{p}}<6 \mathrm{~nm}$ from the time it takes to grow past successive size thresholds, i.e.

$\mathrm{GR}^{i j}=\frac{D_{\text {threshold }}^{j}-D_{\text {threshold }}^{i}}{\Delta t^{i j}}$

where $D_{\text {threshold }}^{i}$ and $D_{\text {threshold }}^{j}$ are the detection thresholds of two CPCs $\left(\mathrm{CPC}_{i}\right.$ and $\left.\mathrm{CPC}_{j}\right)$, with $D_{\text {threshold }}^{j}>D_{\text {threshold }}^{i}$, and $\Delta t^{i j}$ being the time delay between the rise of the two CPCs (Sihto et al., 2006; Riipinen et al., 2007). Figure 1 shows the time series of the CPC battery and CIMS data during a typical $\alpha$-pinene experiment.

The accuracy of the growth rate calculated with Eq. (1) strongly depends on the choice of the detection thresholds and on the point of measurement of the time delay. The detection threshold of a CPC is generally defined as the $D_{50}$ of the cutoff curve, corresponding to the particle diameter for which the CPC has a counting efficiency of $50 \%$. However, one has to keep in mind that the number of particles measured by one CPC is given by the convolution of the particle size distribution and the actual CPC cutoff curve which does not follow an ideal step function.

If $t^{i}$ and $t^{j}$ are the times at which the same concentration of particles (within $1 \mathrm{~cm}^{-3}$ ) is measured by $\mathrm{CPC}_{i}$ and $\mathrm{CPC}_{j}$, we can define $\Delta t^{i j}=t^{j}-t^{i}$. As we will discuss below, if the cutoff curves of the $\mathrm{CPC}_{i}$ and $\mathrm{CPC}_{j}$ do not have the same shape in their detection efficiencies, the time delay $\Delta t^{i j}$ varies over time as the particle diameters grow, resulting in a variation in time for the calculated GR from Eq. (1). 


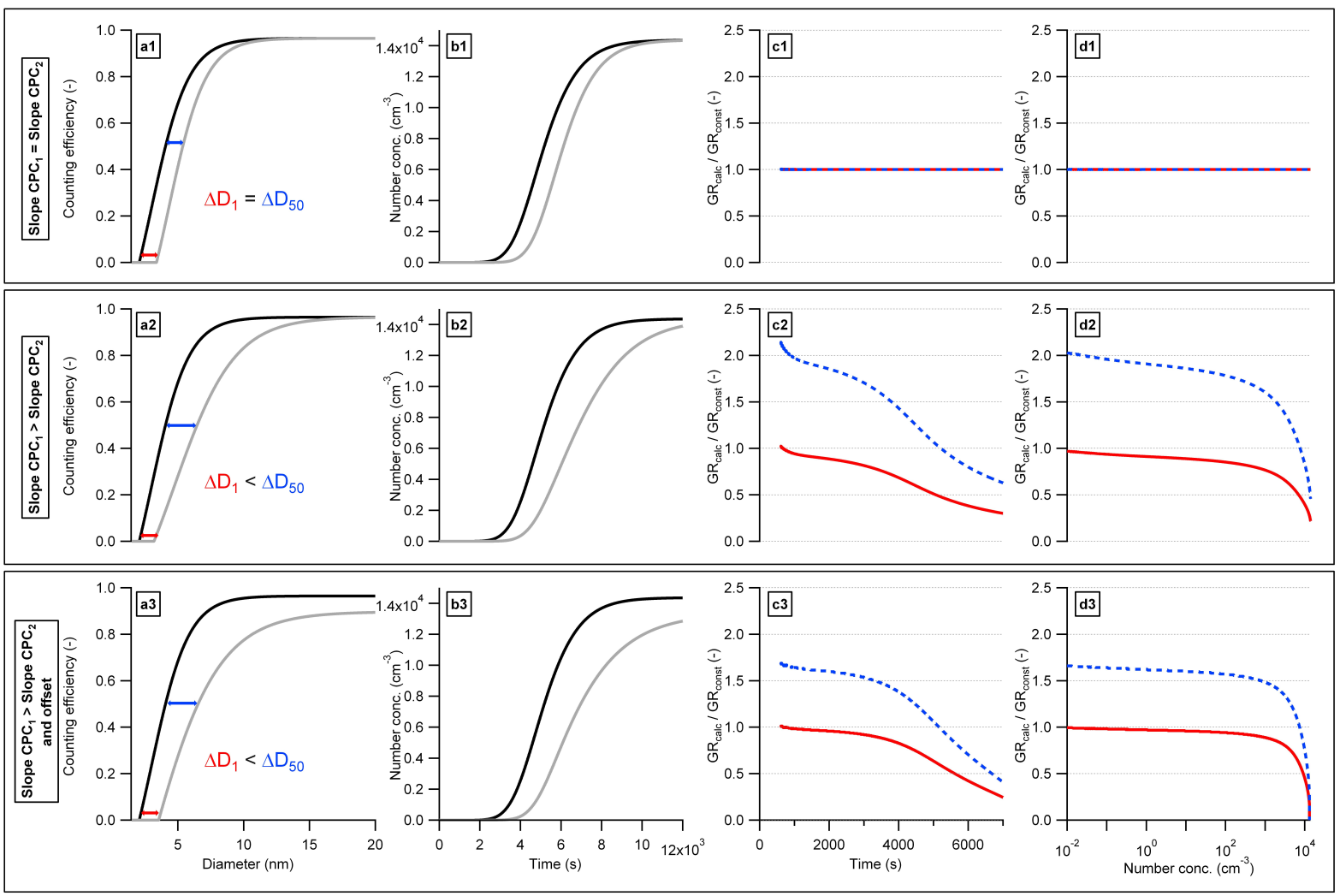

$\begin{array}{llll}-\mathrm{CPC}_{1} & -\mathrm{CPC}_{2} & -- \text { Using } \Delta \mathrm{D}_{50} & \text { - Using } \Delta \mathrm{D}_{1}\end{array}$

Fig. 2. Simulation of the number concentration measurement and growth rate calculation obtained using Eq. (1) and three couples of CPCs with different relations between their efficiency curves (1: Same slopes; 2: Different slopes; 3: Different slopes and offset). (a) Cutoff curves of the two CPCs. (b) Number concentration measured by the CPCs. (c) and (d) ratio between the GR calc $_{\text {and the actual GR }}$ const (constant value in the simulation) using the $D_{50}$ (blue dashed line) or the $D_{1}$ (red solid line) in Eq. (1) as a function of time (c) and as a function of the particle number concentration (d).

Here we propose a new method that is based on a conscientious choice of the detection threshold and of the time delay $\Delta t^{i j}$ : instead of using the $D_{50}$ we use the detection threshold $D_{1}$ (diameter at which the CPC has a counting efficiency of $1 \%$ ) and we calculate the onset time delay $\Delta t^{i j}$ at the initial rise of the CPCs signals (see below for a detailed discussion).

In the following discussion we will demonstrate how the choices of $D_{1}$ and of the onset time delay $\Delta t^{i j}$ are preferable to the choice of $D_{50}$ and of any other point of measurement of the time delay. In addition, because $D_{1}$ is smaller than $D_{50}$, this method will also allow us to extend the growth rate calculation to a smaller range of particle diameters without the necessity for changing the CPC cutoff sizes.

To better understand how the choice of the detection threshold and of the time at which we measure the $\Delta t^{i j}$ influences the growth rate calculation we simulated the growth rate measurement performed by three pairs of CPCs with different relations between their efficiency curves (see Fig. A1). We simulated a chamber experiment with a growing Gaussian distribution $(\sigma=1.5)$. In order to observe the appearance of the particles in the CPCs from almost $0 \mathrm{~cm}^{-3}$ the median of the Gaussian distribution is initially set to a value such that almost the whole size distribution is out of the detection limit of the CPCs (less than $1 \%$ of the mode maximum is left at the $D_{1}$ of the CPCs). For the sake of simplicity the distribution grows at constant growth rate, $\mathrm{GR}_{\text {const }}=$ $5 \mathrm{~nm} \mathrm{~h}^{-1}$, and coagulation and wall losses are neglected.

The results reported in Fig. 2 show that, if the CPC efficiency curves have different slopes, the calculated growth rate $\left(\mathrm{GR}_{\text {calc }}\right)$ changes both over time (vertical panel c) and as the number concentration increases (vertical panel d). Nevertheless, the $D_{1}$ method correctly calculates the growth rate at the beginning of the detection (i.e., $\mathrm{GR}_{\text {calc }} / \mathrm{GR}_{\text {const }}=1$, Fig. 2). Thus, the beginning of the detection is the point in time when we should measure the onset time delay $\Delta t^{i j}$ between the CPCs to correctly calculate the growth rates with Eq. (1). A similar analysis was conducted for CPCs using different working fluids revealing the effective growth rate of nanoparticles with respect to water and butanol (Kulmala et al., 2007; Riipinen et al., 2009).

The simulation also reveals that, in the realistic case of two CPCs that have an offset between the two efficiency curves 
at large particle diameters (possibly due to different internal losses or errors in the aerosol flow reading/setting), the growth rate calculation using the $D_{50}$ is only accurate in a single point in time which is a priori unknown (horizontal panel 3).

Based on these results we decided to calculate the growth rates from the CPC battery by applying the $D_{1}$ method to the CPC battery data, obtaining size dependent growth rates in three size ranges $(1.5-2 \mathrm{~nm} ; 2-3 \mathrm{~nm} ; 3-6 \mathrm{~nm})$. For each experiment we estimated the onset $\Delta t^{i j}$ at particle concentration $N=0$. This is determined measuring the $\Delta t^{i j}$ between the CPCs at each integer particle concentration between $N_{\text {min }}$ and $N_{\max }$ and applying a quadratic polynomial fitting to obtain the value of $\Delta t^{i j}$ at $N=0$. The value of $N_{\min }$ is set equal to $10 \mathrm{~cm}^{-3}$ to avoid low signal to noise ratios; $N_{\max }$ is determined for each individual experiment and is calculated as 10 times the standard deviation of the PSM base line over a period of $5 \mathrm{~min}$ before the lights went on; the choice of $N_{\max }$ does not strongly affect the value of onset $\Delta t^{i j}$.

The error in the growth rate calculation derives from the uncertainties in both measurements of $D_{1}$ and $\Delta t^{i j}$. The uncertainty in $D_{1}$ of the two CPCs is mainly due to calibration uncertainties, such as diffusion loss corrections, flow rate measurements and transfer function of the differential mobility analyzer used for the calibration, which have an overall uncertainty assumed to be smaller than $20 \%$. We assume that a sensitivity of the efficiency curves to particle composition and charge would affect the two CPCs in a similar manner, resulting in a comparable shift in the diameter range for both CPCs, preserving the $\Delta D_{1}$ within $20 \%$. The maximum relative error in $\Delta t^{i j}$ is assumed to be equal to the largest of the relative residuals of the quadratic fitting on the $\Delta t^{i j}$.

\subsubsection{Growth rates from the SMPS measurements}

For particles with $D_{\mathrm{p}}>6 \mathrm{~nm}$, the growth rates were retrieved from the SMPS measurements. The SMPS concentrations were firstly corrected for diffusion losses in the sampling line and in the DMA column and for the CPC counting efficiency. Subsequently the mode diameter was determined by fitting a Gaussian distribution to the $\mathrm{d} N / \mathrm{d} \log D_{\mathrm{p}}$ data. Rather than determining the growth rates using the time evolution of the mode diameter we calculated the particle growth rates following an approach similar to the one used to obtain the growth rates from the CPC battery, i.e., looking at the time delay of the onset of particles in the largest size bins of the SMPS. Here the SMPS leading edge diameter is defined as the diameter corresponding to the size bin at which the fitted Gaussian size distribution reaches $1 \%$ of the concentration measured in the mode diameter bin. The growth rates are then retrieved from the time evolution of the leading edge diameter.

In Fig. 3a, we show a comparison between the leading edge diameters and the mode diameters for all the $\alpha$-pinene experiments. Figure $3 \mathrm{~b}$ depicts the comparison between the
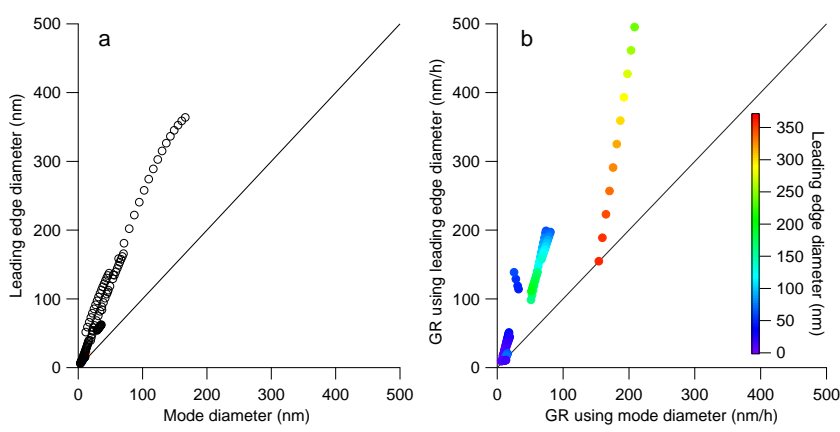

Fig. 3. Leading edge diameter versus mode diameter obtained from the SMPS data (a). Comparison of the SMPS growth rates calculated using the corresponding leading edge and mode diameters of (a), color coded for leading edge diameter (b). $1: 1$ lines are plotted as solid lines.

growth rates calculated from the leading edge diameters and from the mode diameters. The choice of the leading edge diameter is superior to the mean diameter for the growth rate analysis of nucleation chamber experiments because of the following two effects. Firstly, once lights are turned on in the chamber, the concentrations of sulfuric acid and oxidized organic compounds build up and the formation rate increases with time until the losses of cluster precursors equals their production rate. This effect shifts the mode of the size distribution to a lower diameter than it would be the case for condensational growth without continuous nucleation. The second effect is the dynamic change of the shape of the size distribution with growth. The size distribution broadens due to the Kelvin effect and the presence of many organic compounds with different saturation vapor pressures, allowing larger particles to grow at a higher rate than smaller particles. In other words the condensational driving force for a specific vapor compound $i$ onto a particle surface of diameter $D_{\mathrm{p}}$ is positive only if the partial pressure of compound $i$ is larger than the equilibrium vapor pressure over the curved particle surface; increasing $D_{\mathrm{p}}$ increases the number of volatile compounds that can condense on particles of diameter $D_{\mathrm{p}}$, speeding up the growth of particles with larger diameters (see results section for a more detailed discussion).

Other techniques exist for accurately determining sizeresolved growth rates (Iida et al., 2008; Yli-Juuti et al., 2011) and the leading edge method was introduced by Kulmala et al. (1998) for ambient new particle formation studies. However, it has its limitations when applied to ambient aerosols. While chamber experiments always start at a number concentration close to zero, the nucleation occurring in the ambient atmosphere happens in the presence of a pre-existing population of particles (with $D_{\mathrm{p}}>10 \mathrm{~nm}$ ) which creates a high background over which the nucleating mode grows without a distinct leading edge. In this study background particles do not hinder the use of the leading edge method; hence, the data 
presented in the following discussion are obtained applying the leading edge method.

\subsubsection{Growth rate enhancement factor $\Gamma$}

In order to quantify the relative contributions to the particle growth by sulfuric acid and by organic compounds, we compared the observed growth rates, obtained from the CPC battery and from the SMPS, with the modeled growth rates expected from the measured sulfuric acid gas phase concentration when assuming that the aerosol growth is driven only by condensation of $\mathrm{H}_{2} \mathrm{SO}_{4}$ and $\mathrm{H}_{2} \mathrm{O}$.

The collision rate $K$ used in the $\mathrm{H}_{2} \mathrm{SO}_{4}$ growth model is

$K=\frac{\pi}{3} K_{n} \beta_{\mathrm{d}}\left(K_{n}, \alpha\right)\left(D_{\mathrm{p}}+D_{\mathrm{v}}\right)^{2}\left(\bar{c}_{\mathrm{p}}^{2}+\bar{c}_{\mathrm{v}}^{2}\right)^{1 / 2} C_{\mathrm{v}}$.

In addition to classical condensation kinetic theory (Seinfeld and Pandis, 2006) it also contains the diameter of the condensing molecule $D_{\mathrm{v}}$ and the diffusion coefficient of the growing particle, which are both relevant when the particle size is comparable to that of the condensing molecule (Nieminen et al., 2010). Subscripts "p" and "v" refer to particle and vapor properties, respectively, $\mathrm{Kn}$ is the Knudsen number, $\beta_{\mathrm{d}}$ is the Fuchs-Sutugin correction factor, $\alpha$ is the accommodation coefficient, $\bar{c}$ is the thermal speed and $C_{\mathrm{v}}$ is the concentration of vapor molecules per unit volume. For sulfuric acid we assume $\alpha=1$, which implies that the maximum condensation rate at a given partial pressure is limited by the kinetic collision rate of sulfuric acid molecules with the growing particles. Under the experimental relative humidity of $50 \%$ the sulfuric acid is thought to be mainly dihydrated (Kurtén et al., 2007), the density is assumed to be $1490 \mathrm{~kg} \mathrm{~m}^{-3}\left(\mathrm{H}_{2} \mathrm{SO}_{4}+2 \mathrm{H}_{2} \mathrm{O}\right)$ and the diffusion coefficient is taken equal to $0.08 \mathrm{~cm}^{2} \mathrm{~s}^{-1}$ (Hanson and Eisele, 2000). Assuming that each collision increases the particle volume by $\Delta V_{\mathrm{p}}=V_{\mathrm{v}}=m_{\mathrm{v}} / \rho_{\mathrm{v}}$, we can write

$$
\frac{\mathrm{d} V_{\mathrm{p}}}{\mathrm{d} t}=\mathrm{KV}_{\mathrm{v}}
$$

and finally calculate the diameter growth rate (GR) as

$$
\mathrm{GR}=\frac{\mathrm{d} D_{\mathrm{p}}}{\mathrm{d} t}=\frac{\mathrm{d} V_{\mathrm{p}} / d t}{\mathrm{~d} V_{\mathrm{p}} / \mathrm{d} D_{\mathrm{p}}}=\frac{\mathrm{KV}_{\mathrm{v}}}{\frac{\pi}{2} D_{\mathrm{p}}^{2}}
$$

For all the measured growth rates from the CPC battery and SMPS ( $\left.\mathrm{GR}_{\text {meas }}\right)$, we calculated the corresponding expected growth rate by sulfuric acid $\left(\mathrm{GR}_{\bmod }\right)$ through Eqs. (2) and (4). To compare correctly $\mathrm{GR}_{\text {meas }}$ with $\mathrm{GR}_{\text {mod }}$ we used the average particle diameter and the average sulfuric acid concentration in Eq. (2) calculated over the same time window used for deriving the growth rate with the SMPS. For the comparison with the observed growth rates from the CPC battery we used the average of the $D_{1}$ of the CPCs for each $\mathrm{CPC}$ battery size range $(1.75,2.5$ and $4.5 \mathrm{~nm})$ and the sulfuric acid average over the time window between the appearance of the particles in the two CPCs.

If we assume that the measured growth rate is due only to sulfuric acid and organic vapors, following the definition proposed by Kuang et al. (2012), we can define and calculate the growth rate enhancement factor due to organic compounds as

$\Gamma=\frac{\mathrm{GR}_{\text {meas }}}{\mathrm{GR}_{\text {mod }}}$

where $\mathrm{GR}_{\text {meas }}$ contains the measured contribution to growth by both sulfuric acid and organic vapors, while $\mathrm{GR}_{\bmod }$ contains the calculated contribution to growth only by sulfuric acid.

\section{Results and discussion}

\subsection{Particle formation rates vs. sulfuric acid concentration}

Figure 4 reports the formation rates as a function of the sulfuric acid concentrations measured in this work, and compares them with the laboratory study of Metzger et al. (2010) and ambient measurements in Hyytiälä, Finland (Sihto et al., 2006). The comparison of the $\alpha$-pinene experiments with the ambient data indicates that $\alpha$-pinene is capable of reproducing the formation rates observed in the boreal forest for similar concentrations of sulfuric acid.

Indeed, our observations do not rule out the possibility that other compounds participate in the particle formation mechanism. The total concentration of organic precursors in a boreal forest is comparable to the $\alpha$-pinene concentration used in these experiments, but other compounds may have been present as contaminants. A recent study (Kirkby et al., 2011) performed in an ultraclean organics free environmental chamber showed that binary sulfuric acid/water nucleation is not capable of reproducing ambient nucleation rates, and the presence of ammonia increased the pure binary nucleation, but saturated at three orders of magnitude lower nucleation rates than the ambient values. For the conditions in our chamber, the organic compounds are the most likely candidates to enhance the formation rates to ambient values, but we cannot elucidate at which stage the organics enter the process of particle formation. The real nucleation mechanism which occurs at molecular level cannot be investigated with the instrumentation available during this work; for this reason we always refer to formation rates rather than to nucleation rates.

The formation rates for the $\alpha$-pinene experiments of Fig. 4 are color coded with the decay rate of $\alpha$-pinene which is a proxy for the NucOrg concentration (using the same notation as used by Metzger et al. (2010), NucOrg represents the organic molecules that participate in the particle formation process). In Fig. 4, a correlation between the particle formation rate and the decay rate of $\alpha$-pinene is hindered by at least 


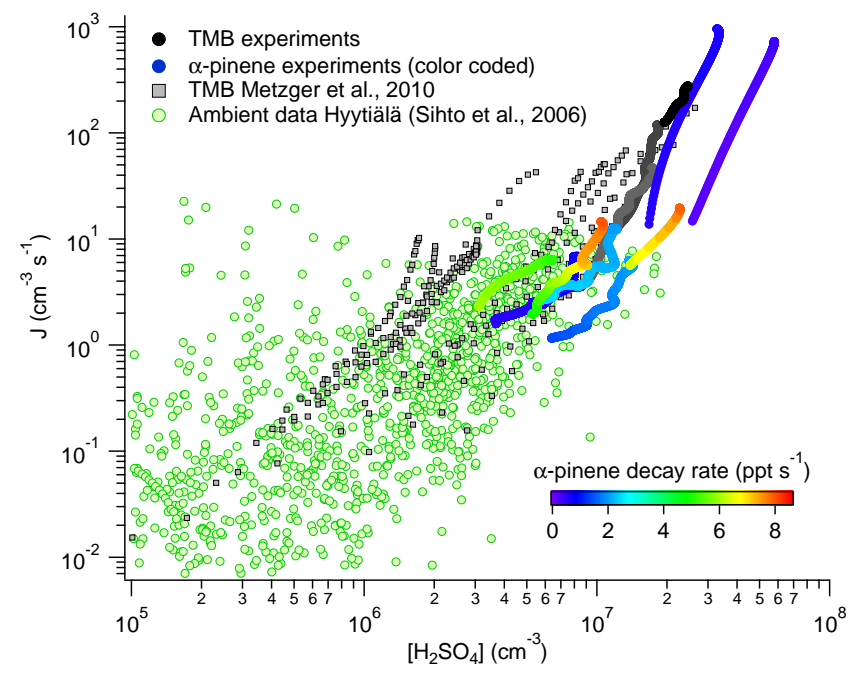

Fig. 4. Colored symbols represent the particle formation rates calculated with the PSM as a function of the sulfuric acid concentration. The $\alpha$-pinene experiments are color coded with the $\alpha$-pinene decay rate. For comparison we plot the TMB data from Metzger et al. (2010) (gray squares) and ambient data measured in Hyytiälä (green circles, Sihto et al., 2006).

two factors: (a) $\alpha$-pinene is oxidized by both $\mathrm{OH}$ and ozone, which generate different families of oxidation products that may participate differently in the particle formation process; (b) additional unmonitored compounds may also contribute to the particle formation.

TMB also appears to be capable of reproducing the formation rates observed in the atmosphere in the same range of sulfuric acid concentrations. The data collected in this work, in which sulfuric acid concentrations were directly measured, agree well with the experiments performed by Metzger et al. (2010), although they all lie at the higher end of the sulfuric acid concentration range of the earlier study $\left(\sim 10^{7} \mathrm{~cm}^{-3}\right)$.

In order to verify the ability of the model used in Metzger et al. (2010) to capture the sulfuric acid concentrations, we repeated the modeling with the same parameters used in that study. Figure 5 compares the time series of the measured and modeled sulfuric acid concentrations. Note that the measured peak concentrations agree within the model and the measurement uncertainties, but the model underestimates the sulfuric acid concentration at the beginning of the experiment. One of the reasons responsible for this behavior is that the model did not include any sulfuric acid background concentration, but as depicted in Fig. 5, the sulfuric acid concentration measured by the CIMS rises at the moment of $\mathrm{SO}_{2}$ injection, even before the UV lights are switched on. This dark production of $\mathrm{H}_{2} \mathrm{SO}_{4}$ was observed throughout the whole measurement campaign. It may be attributed either to heterogeneous reactions on the Teflon walls of the chamber or in case of the $\alpha$-pinene experiments to the $\mathrm{OH}$ formation during the

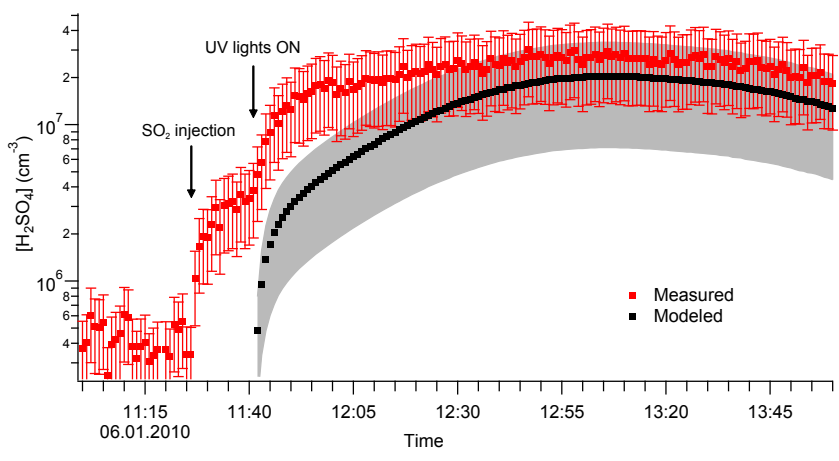

Fig. 5. Measured sulfuric acid time evolution during TMB 1 experiment (red markers) and modeled sulfuric acid concentration (black) obtained with the kinetic model reported by Metzger et al. (2010). Uncertainties are estimated to be $50 \%$ on sulfuric acid (red error bars) and $65 \%$ on modeled data (gray shadow, see Metzger et al., 2010). Injection of $\mathrm{SO}_{2}$ in the chamber produced an increase in the background concentration of sulfuric acid which was not included in the model used by Metzger et al. (2010).

ozonolysis of $\alpha$-pinene. Further experiments are needed to discriminate between these processes. As a result of this dark production, the background $\mathrm{H}_{2} \mathrm{SO}_{4}$ concentration varied between $2 \times 10^{5} \mathrm{~cm}^{-3}$ and $3 \times 10^{6} \mathrm{~cm}^{-3}$ depending on the $\mathrm{SO}_{2}$ initial concentration. Another possible reason for underestimating the sulfuric acid concentration is that the lifetime of the sulfuric acid used in the model by Metzger et al. (2010) was only about half of the sulfuric acid lifetime estimated from the decay rate of the sulfuric acid concentration measured with the CIMS instruments.

In conclusion, the observed background concentration of sulfuric acid (which is a function of the initial $\mathrm{SO}_{2}$ concentration) indicates that the modeled sulfuric acid concentration of Metzger et al. (2010) might have been underestimated by a few times $10^{5} \mathrm{~cm}^{-3}$ for the experiments with low $\mathrm{SO}_{2}$ and up to a maximum of $10^{7} \mathrm{~cm}^{-3}$ for the experiments in the presence of high $\mathrm{SO}_{2}$. However, this relative shift towards higher sulfuric acid concentrations does not change the main results presented in the previous work, which suggested that the role of NucOrg is crucial for the overall process of particle formation.

\subsection{Role of sulfuric acid and organic vapors for size dependent growth rates}

Figure 6 depicts the growth rate enhancement factor as a function of the diameter determined from the CPC battery and SMPS during the $\alpha$-pinene experiments. $\Gamma$ values are found between $\sim 1$ and 2000 , indicating that, after the reaction of a few ppbv of $\alpha$-pinene, the growth due to organic compounds dominates throughout the particle size distribution. The results show that even at particle diameters below $2 \mathrm{~nm}$ a large fraction (up to more than $90 \%$ ) of the observed growth is attributable to organic vapors, supporting 


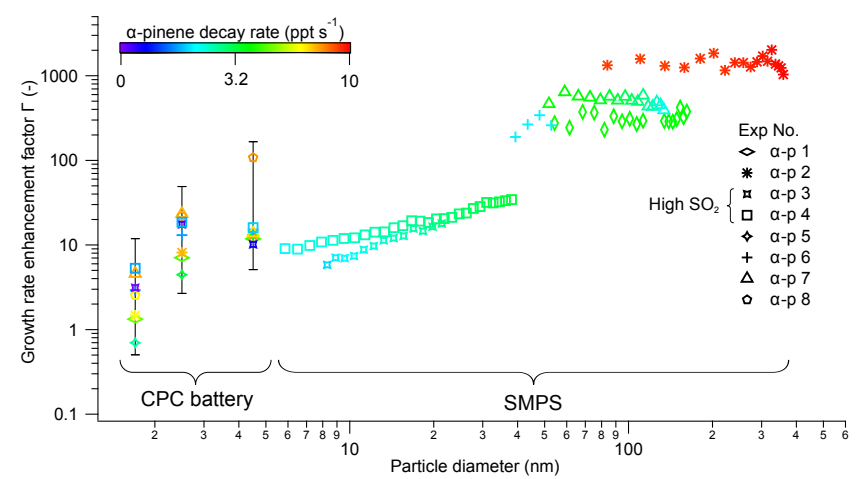

Fig. 6. Growth rate enhancement factors $\Gamma$ as a function of diameter from CPC battery and SMPS data. Different markers correspond to different experiments, color coded with the decay rate of $\alpha$-pinene. Note that the experiments $\alpha$-p 3 and $\alpha$-p 4 were performed with injection of $5 \mathrm{ppbv}$ of $\mathrm{SO}_{2}$ producing a higher sulfuric acid concentration compared to the other experiments, hence influencing the corresponding $\Gamma$ results. $\Gamma$ values were not available from the SMPS measurements during two experiments, $\alpha-\mathrm{p} 5$ and $\alpha-\mathrm{p} 8$, because of the poor quality of the SMPS data during these experiments.

the findings of other recent publications (Sihto et al., 2006; Yli-Juuti et al., 2011; Kuang et al., 2012).

The general trend of Fig. 6 shows that, as the diameter of the particles increases, the organic contribution to the growth $(\Gamma)$ increases, indicating that the condensation driving force $\left(p-p_{\mathrm{eq}}\right)$ for organics increases as the particles grow (Eq. 6), either by increasing the partial pressure, $p$, or by decreasing the equilibrium vapor pressure, $p_{\mathrm{eq}}$, due to the growth of particle size (Kelvin effect), or due to changes in particle chemistry (Roult's law). The attempt of disentangling the effects of $p$ and $p_{\text {eq }}$ on particle growth is further hindered by the broad family of condensable organic compounds that are formed during the time of the experiment, the temporal effect; i.e., while the particles grow to larger diameters both the chemical composition and the concentration of the condensable organic compounds change.

A qualitative distinction between the temporal effect and the other effects is revealed in Fig. 3. It contains the direct evidence of the role played by the particle size and composition in lowering the equilibrium vapor pressure when the particles grow. Figure $3 \mathrm{~b}$ shows that the growth rate of the leading edge (big particles) is larger than the growth rate of the mode diameter (smaller particles) at a given point in time, i.e., for particles exposed to the same distribution of vapors. The difference between the two growth rates becomes smaller as the particles grow (color code in Fig. 3) since the relative differences of both Kelvin effect and particle composition become smaller for larger particles.

The difference between the measured GR and the model GR due to sulfuric acid $\left(\mathrm{GR}_{\text {meas }}-\mathrm{GR}_{\text {mod }}\right.$, see Sect. 2.1.4) is equal to the growth rate attributable to condensation of organic compounds. Plotting growth rates due to organic compounds as a function of sulfuric acid concentration for parti-

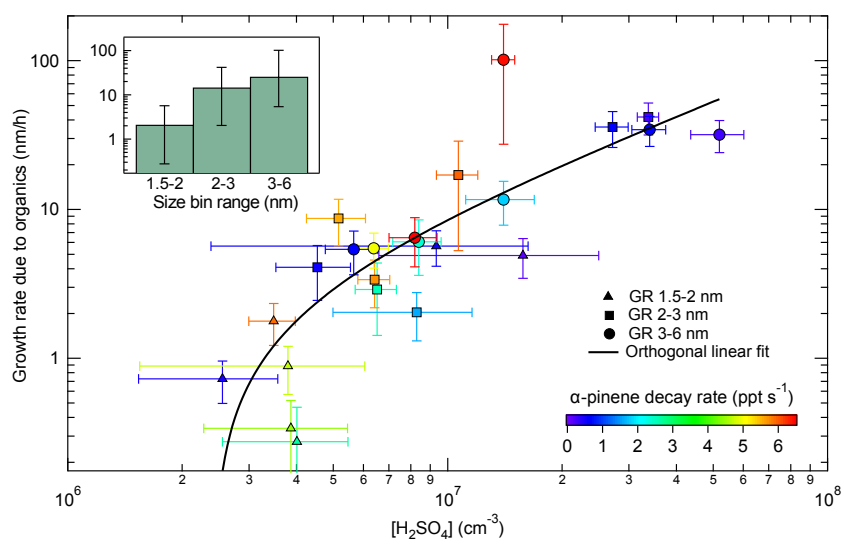

Fig. 7. Initial growth rates attributable to organic compounds observed with the CPC battery as a function of sulfuric acid concentration color coded with $\alpha$-pinene decay rate (different markers correspond to different size ranges). The error bars represent the standard deviations. Large error bars on the sulfuric acid concentrations in the $1.5-2 \mathrm{~nm}$ size range are caused by the fact that $\left[\mathrm{H}_{2} \mathrm{SO}_{4}\right]$ had not reached its plateau value at the early stage of the experiment when these GR values had been determined. The inset shows the average growth rates attributable to organics as a function of the particle diameter, the bars indicate the minimum and the maximum GR in each size bin.

cles smaller than $6 \mathrm{~nm}$ allows observing the contribution of organic compounds to the early stage particle growth from another perspective. Figure 7 shows the growth rates due to organic compounds retrieved from the CPC battery as a function of sulfuric acid in three separate size bins $(1.5-2 \mathrm{~nm}$, $2-3 \mathrm{~nm}$ and 3-6nm), color coded with the decay rate of $\alpha-$ pinene. The error bars correspond to the standard deviation of the sulfuric acid concentration (x-axis) and to the estimated error of the GR (y-axis, see Sect. 2.1).

The first and most important feature of Fig. 7 is that, in this size range $(1.5-6 \mathrm{~nm})$, the sulfuric acid seems to enhance the growth rate by organic compounds. Within a single size bin the growth rate due to organics is higher when the sulfuric acid concentration is higher, independently of the $\alpha$-pinene decay rate (color code in Fig. 7). Although the mechanism related to this observation remains uncertain, we can make some observations from Figs. 6 and 7. When sulfuric acid condenses onto growing particles, it lowers the organic activity (decreasing the organic molar fraction) and increases the size of the particle. Both of these effects decrease the equilibrium vapor pressure of the condensing organics. At high sulfuric acid concentrations the addition of sulfuric acid molecules to the growing particle is accelerated, this might speed up the process of lowering the equilibrium vapor pressure and consequently speed up the condensation of organics. Theoretical calculations show that gas-phase oxidation can produce organic compounds with low enough saturation vapor pressures which are able to condense onto particles with diameter of a few nanometers (Donahue et al., 2011; Pierce et al., 2011). 
On the other hand, Fig. 6 suggests that the growing particles are mainly composed of organics; $\Gamma \sim 10$ for $2-6 \mathrm{~nm}$ particles means that only $\sim 10 \%$ of the GR is due to sulfuric acid. Hence, sulfuric acid produces minor changes of the particle size and organic activities, resulting in small changes in the Kelvin and Raoult terms. This opens the door to other possible mechanisms which may contribute to particle growth, such as reactive uptake, which has already been observed to contribute to the growth of organic aerosol (e.g., Smith et al., 2010; Wang et al., 2010). Sulfuric acid condensation may enhance the uptake of organic molecules via increasing the solution acidity (Gao et al., 2004) and/or increasing its ionic strength (Kroll et al., 2005).

The importance of reactive uptake in growth of nanoparticles is supported by another observation: the weak correlation between the growth rates due to organics and the decay rate of $\alpha$-pinene (color code in Fig. 7) suggests a decoupling of the growth mechanism from pure gas-phase oxidation processes. Analogously, a weak correlation is also found between $\Gamma$ and the decay rate of $\alpha$-pinene for the CPC battery data (Fig. 6). The correlation between $\Gamma$ and the decay rate of $\alpha$-pinene becomes more evident at particle sizes larger than $6 \mathrm{~nm}$ (SMPS data in Fig. 6), where the Kelvin effect becomes smaller and a larger mass of the absorbing particle decreases the activity of organic compounds; at the same time, organic compounds, that have low saturation vapor pressures accumulate increasing the driving force $p-p_{\text {eq }}$ (Eq. 6).

For small particles $\left(D_{\mathrm{p}}<6 \mathrm{~nm}\right)$ the $\alpha$-pinene decay rate seems to correlate with GR only in the case of the largest outlier of Fig. $7\left(\mathrm{GR} \sim 100 \mathrm{~nm} \mathrm{~h}^{-1}\right)$, which is also associated with a large uncertainty on the GR. This outlier is a growth rate measurement performed during experiment $\alpha$ p 8, conducted at high initial $\alpha$-pinene concentrations, which followed a high $\mathrm{NO}_{\mathrm{x}}$ experiment $(\alpha-\mathrm{p} 7)$. The latter might have produced high HONO concentrations which, together with other unmonitored contaminant compounds left over from the previous experiment, might have resulted in strong $\alpha$-pinene decay and thus enhanced the growth rate.

Figure 7 also shows that the absolute growth rates increase with particle size (inset of Fig. 7). This observation would fit with the nano-Köhler theory, which, assuming multi-component organic condensation, predicts an increasing GR with particle size (Kulmala et al., 2004b). Reactive uptake might also fit with this observation: these reactions would allow the first organic molecules to bind with the sulfuric acid molecules overcoming the initial barrier for condensation and increasing the particle diameter to sizes where further condensation of organic compounds is permitted.

The large uncertainties reported in Figs. 6 and 7, together with the lack of knowledge about saturation vapor pressures and the unknown partial pressures of the species involved, do not allow us to conclude whether organic compounds are the only substances responsible for the observed growth rate enhancement factors $\Gamma$. Kirkby et al. (2011) recently showed that trace amounts such as ammonia or amines may have a strong influence on the particle formation process; ammonium or aminium salts (Smith et al., 2010; Wang et al., 2010) might indeed be involved in the initial growth as well, contributing to the observed variability in the growth rate enhancement factors.

\section{Summary and conclusions}

We measured the particle formation rates and growth rates of particles under atmospherically relevant concentrations of sulfuric acid and organic vapors. The observed particle formation rates were found to be in the same range as the formation rates measured in the atmosphere at the corresponding sulfuric acid concentrations. These results are in agreement with the observations of our previous work (Metzger et al., 2010), where no CIMS was available and the sulfuric acid concentrations were estimated using a kinetic model.

We developed a new method for the analysis of size resolved growth rate measurements using a CPC battery, and we optimized the SMPS growth rates analysis for chamber nucleation experiments, and compared the new approach with the traditional ones.

The size resolved growth rate analysis allowed us to study the contribution of sulfuric acid and organic compounds to aerosol growth. The measured growth rates were compared with the kinetically limited growth rates by sulfuric acid. This comparison demonstrated that, in the presence of sulfuric acid and $\alpha$-pinene, the growth due to organic compounds dominates nearly the entire size distribution. The observation that the organic contribution to growth increases as the diameter of the particles increases supports the multiple activation mechanism predicted by the nano-Köhler theory.

We also observed that, once isolated, the contribution of organic compounds to growth seems to be enhanced by the sulfuric acid concentration. The mechanism responsible for this observation remains to be elucidated through further chamber experiments. If confirmed, its inclusion in global models might change the present estimations of the anthropogenic contribution to the formation of secondary aerosol.

The considerations made about the latter effect and the weak correlation of the initial growth rates with the decay rate of $\alpha$-pinene suggest that other mechanisms, different from pure gas-phase chemistry, may participate in the initial steps of growth (i.e., reactive uptake).

At present, the uncertainties in the measurements and in the thermodynamic properties of the condensing species do not allow us to estimate the relative contribution of gasphase chemistry and reactive uptake to aerosol growth. Further chamber experiments in the presence of sensitive instrumentation for the particle growth rate measurements together with advanced growth rates analysis tools are needed to provide better size resolved growth rate measurements in order to further constrain uncertainties in global aerosol, chemistry and climate models. 
Table A1. Fitting parameters of Eq. (A1) and retrieved $D_{0}, D_{1}$ for the three TSI CPCs of the CPC battery.

\begin{tabular}{lrrrrr}
\hline CPC name & $a(-)$ & $b(\mathrm{~nm})$ & $c(\mathrm{~nm})$ & $D_{0}(\mathrm{~nm})$ & $D_{1}(\mathrm{~nm})$ \\
\hline TSI 3776 & 0.98 & 1.87 & 1.93 & 1.90 & 1.92 \\
TSI 3772 & 0.91 & 2.81 & 3.19 & 3.10 & 3.14 \\
TSI 3010 & 0.91 & 5.94 & 5.12 & 6.43 & 6.48 \\
\hline
\end{tabular}

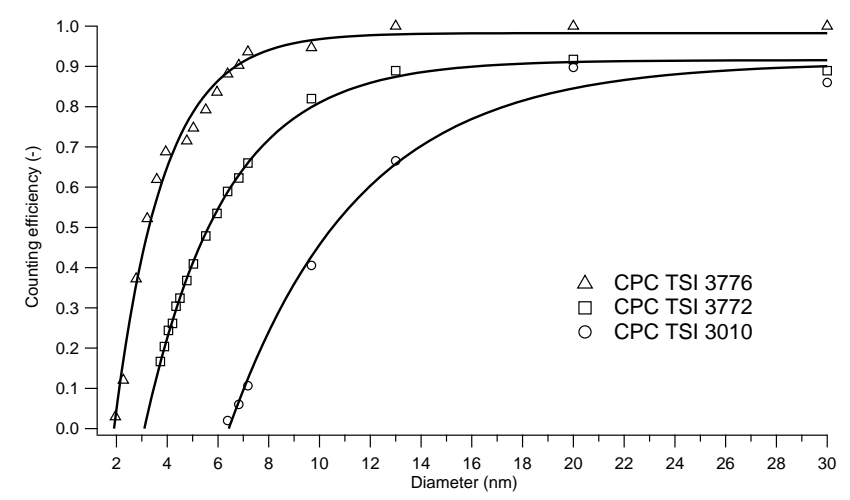

Fig. A1. Counting efficiency curves (Eq. A1) as a function of the mobility diameter for the CPCs used to determine the initial GR (particles with $D_{\mathrm{p}}<6 \mathrm{~nm}$ ).

\section{Appendix A}

\section{CPC calibration and sulfuric acid measurement}

The growth rate measurements of particles smaller than $6 \mathrm{~nm}$ were performed with the CPC battery. This method requires accurate calibration of the CPCs in the laboratory. We used a high resolution Herrmann DMA (Herrmann et al., 2000) to classify $\mathrm{WO}_{\mathrm{x}}$ particles smaller than $4 \mathrm{~nm}$. A short column DMA (home-built DMA with similar specifications to TSI model 3085 nano-DMA) was used to classify particles larger than $4 \mathrm{~nm}$. The measured counting efficiencies (Fig. A1) of the three TSI CPCs are fitted with the following threeparameter equation that is based on the fit equation proposed by Stolzenburg and McMurry (1991)

$\begin{array}{ll}\eta=a-\exp \left(\left(b-D_{\mathrm{p}}\right) / c\right), & D_{\mathrm{p}}>D_{0} \\ \eta=0, & D_{\mathrm{p}}<D_{0}\end{array}$

with $D_{0}=b-c \ln (a)$.

Table A1 contains the fitting parameters and the corresponding $D_{0}$ and $D_{1}$ for the three TSI CPCs. For the PSM we assumed a nominal $D_{1}=1.5 \mathrm{~nm}$ assuming that this is the critical cluster size at which particles appear (Vuollekoski et al., 2010; Vanhanen et al., 2011).

For simplicity, we always refer to nominal values of $D_{1}: 2$, 3 and $6 \mathrm{~nm}$ for the CPCs used in the CPC battery but the actual growth rate calculation is performed with the $D_{1}$ values reported in Table A1.

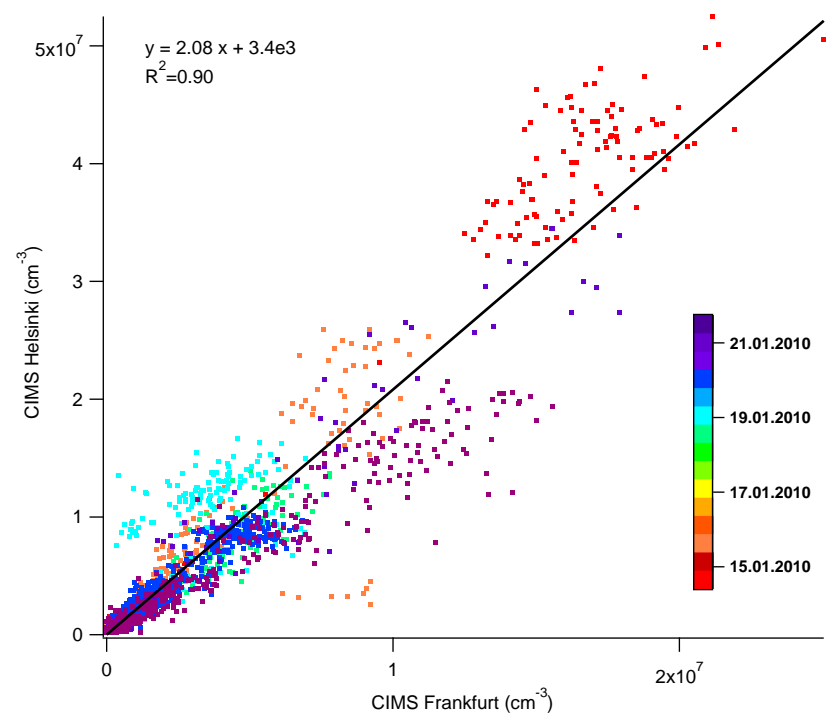

Fig. A2. Correlation between the $\mathrm{H}_{2} \mathrm{SO}_{4}$ measurements of the two CIMS color coded by date.

The two CIMS instruments employed in our study were independently calibrated. The concentrations measured by the two instruments correlate with a slope of 2.08 averaged over the entire experimental campaign (Fig. A2). The best estimate of $\left[\mathrm{H}_{2} \mathrm{SO}_{4}\right]$ was determined as the arithmetic mean of the concentrations measured by the two CIMS instruments. The reason for the average deviation by a factor of 2.08 between the two measurements is currently not resolved. Both instruments were operated with identical inlets and similar sample flow rates. Further inter-comparisons and intercalibrations are necessary to resolve the differences. The CIMS $\mathrm{H}_{2} \mathrm{SO}_{4}$ instruments have reported a factor of two total uncertainty (Frankfurt-CIMS, Kirkby et al., 2011) and $\pm 35 \%$ (Helsinki-CIMS, Petäjä et al., 2009), therefore the measurements do agree within these uncertainties. The CIMS instruments run at the same time during the $\alpha$-pinene experiments while only the Frankfurt CIMS was running during the TMB experiments. The CIMS from University of Helsinki was calibrated by measurement of $\mathrm{OH}$ generated from photolysis of a known amount of water vapor. More information is presented in Mauldin et al. (2001) and Petäjä et al. (2009). The CIMS from University of Frankfurt was calibrated by an external set-up which provided a known concentration of $\mathrm{H}_{2} \mathrm{SO}_{4}$. The $\mathrm{H}_{2} \mathrm{SO}_{4}$ was produced by illuminating a mixture of $\mathrm{SO}_{2}, \mathrm{H}_{2} \mathrm{O}, \mathrm{O}_{2}$ and $\mathrm{N}_{2}$ with UV light (see Kürten et al. (2012) for details).

Acknowledgements. This work was supported by the EC Seventh Framework Programmes under grant agreement nos. 215072 (Marie Curie Initial Training Network, "CLOUD-ITN") and 228335 (EUROCHAMP), as well as the Swiss National Science Foundation (project no. 206621_125025 and 206620_130527), the German Federal Ministry of Education and Research (project 
no. 01LK0902A), the ERC-Advanced Grant "ATMNUCLE" no. 227463, and the Academy of Finland Center of Excellence program (project no. 1118615 and 139656).

Edited by: J. H. Seinfeld

\section{References}

Albrecht, B. A.: Aerosols, cloud microphysics, and fractional cloudiness, Science, 245, 1227-1230, 1989.

Baron, P. A. and Willeke, K.: Aerosol measurement. Principles, Techniques and Applications, second ed. Wiley Interscience, New York, 2001.

Berndt, T., Stratmann, F., Sipilä, M., Vanhanen, J., Petäjä, T., Mikkilä, J., Grüner, A., Spindler, G., Lee Mauldin III, R., Curtius, J., Kulmala, M., and Heintzenberg, J.: Laboratory study on new particle formation from the reaction $\mathrm{OH}+\mathrm{SO}_{2}$ : influence of experimental conditions, $\mathrm{H}_{2} \mathrm{O}$ vapour, $\mathrm{NH}_{3}$ and the amine tert-butylamine on the overall process, Atmos. Chem. Phys., 10, 7101-7116, doi:10.5194/acp-10-7101-2010, 2010.

Berresheim, H., Elste, T., Plass-Dülmer, C., Eisele, F. L., and Tanner D. J.: Chemical ionization mass spectrometer for longterm measurements of atmospheric $\mathrm{OH}$ and $\mathrm{H}_{2} \mathrm{SO}_{4}$, Int. J. Mass. Spec., 202, 91-109, 2000.

Curtius, J.: Nucleation of atmospheric aerosol particles, C. R. Phys., 7, 1027-1045, 2006.

Donahue, N. M., Trump, E. R., Pierce, J. R., and Riipinen, I.: Theoretical constraints on pure vapor-pressure driven condensation of organics to ultrafine particles, Geophys. Res. Lett., 38, L16801, doi:10.1029/2011GL048115, 2011.

Eisele, F. L. and Tanner, D. J.: Measurement of the gas phase concentration of $\mathrm{H}_{2} \mathrm{SO}_{4}$ and methane sulfonic acid and estimates of $\mathrm{H}_{2} \mathrm{SO}_{4}$ production and loss in the atmosphere, J. Geophys. Res., 98, 9001, doi:10.1029/93JD00031, 1993.

Gao, S., Nga, L. N., Keywood, M., Varutbangkul, V., Bahreini, R., Nenes, A., He, J., Yoo, K. Y., Beauchamp, J. L., Hodyss, R. P., Flagan, R. C., and Seinfeld, J. H.: Particle phase acidity and oligomer formation in secondary organic aerosol, Environ. Sci. Technol., 38, 6582-6589, 2004.

Hanson, D. R. and Eisele, F. L.: Diffusion of $\mathrm{H}_{2} \mathrm{SO}_{4}$ in humidified nitrogen: Hydrated $\mathrm{H}_{2} \mathrm{SO}_{4}$, J. Phys. Chem. A, 104, 1715-1719, 2000.

Herrmann, W., Eichler, T., Bernardo, N., and Fernandez de la Mora, J.: Turbulent transition arises at Re 35000 in a short Vienna-type DMA with a large laminarizing inlet, Abstract to the annual conference of the AAAR, St. Louis, MO, 6-10 October, 2000.

Iida, K., Stolzenburg, M. R., McMurry, P. H., and Smith, J. N.: Estimating nanoparticle growth rates from sizedependent charged fractions: Analysis of new particle formation events in Mexico City, J. Geophys. Res., 113, D05207, doi:10.1029/2007JD009260, 2008.

IPCC, Climate Change 2007: the Physical Science Basis. Contribution of Working Group I to the Fourth Assessment Report of the Intergovernmental Panel on Climate Change, Cambridge Univ. Press, 2007.

Kerminen, V.-M. and Kulmala, M.: Analytical formulae connecting the "real" and the "apparent" nucleation rate and the nuclei number concentration for atmospheric nucleation events, J. Aerosol Sci., 33, 609-622, 2002.
Kerminen, V.-M., Pirjola, L., and Kulmala, M.: How significantly does coagulation scavenging limit atmospheric particle production, J. Geophys. Res., 106, 24119-24125, 2001.

Kirkby, J., Curtius, J., Almeida, J., Dunne, E., Duplissy, J., Ehrhart, S., Franchin, A., Gagne, S., Ickes, L., Kürten, A., Kupc, A., Metzger, A., Riccobono, F., Rondo, L., Schobesberger, S., Tsagkogeorgas, G., Wimmer, D., Amorim, A., Bianchi, F., Breitenlechner, M., David, A., Dommen, J., Downard, A., Ehn, M., Flagan, R. C., Haider, S., Hansel, A., Hauser, D., Jud, W., Junninen, H., Kreissl, F., Kvashin, A., Laaksonen, A., Lehtipalo, K., Lima, J., Lovejoy, E. R., Makhmutov, V., Mathot, S., Mikkila, J., Minginette, P., Mogo, S., Nieminen, T., Onnela, A., Pereira, P., Petäjä, T., Schnitzhofer, R., Seinfeld, J. H., Sipila, M., Stozhkov, Y., Stratmann, F., Tome, A., Vanhanen, J., Viisanen, Y., Vrtala, A., Wagner, P. E., Walther, H., Weingartner, E., Wex, H., Winkler, P. M., Carslaw, K. S., Worsnop, D. R., Baltensperger, U., and Kulmala, M.: Role of sulphuric acid, ammonia and galactic cosmic rays in atmospheric aerosol nucleation, Nature, 476, 429-433, 2011.

Köhler, H.: The nucleus in and the growth of hygroscopic droplets, T. Faraday Soc., 43, 1152-1161, 1936.

Kroll, J. H., Ng, N. L., Murphy, S. M., Varutbangkul, V., Flagan, R. C., and Seinfeld, J. H.: Chamber studies of secondary organic aerosol growth by reactive uptake of simple carbonyl compounds, J. Geophys. Res. Atmos., 110, D23207, doi:10.1029/2005JD006004, 2005.

Kuang, C., Chen, M., Zhao, J., Smith, J., McMurry, P. H., and Wang, J.: Size and time-resolved growth rate measurements of 1 to 5 nm freshly formed atmospheric nuclei, Atmos. Chem. Phys., 12, 3573-3589, doi:10.5194/acp-12-3573-2012, 2012.

Kulmala, M. and Kerminen, V.-M.: On the formation and growth of atmospheric nanoparticles, Atmos. Res., 90, 132-150, 2008.

Kulmala, M., Toivonen, A., Mäkelä, J. M., and Laaksonen, A.: Analysis of the growth of nucleation mode particles observed in Boreal forest, Tellus B, 50, 449-462, 1998.

Kulmala, M., Vehkamäki, H., Petäjä, T., Dal Maso, M., Lauri, A., Kerminen, V.-M., Birmili, W., and McMurry, P. H.: Formation and growth of ultrafine atmospheric particles: A review of observations, J. Aerosol Sci., 35, 143-176, 2004a.

Kulmala, M., Kerminen, V.-M., Anttila, T., Laaksonen, A., and O'Dowd, C. D.: Organic aerosol formation via sulphate cluster activation, J. Geophys. Res., 109, D04205, doi:10.1029/2003JD003961, 2004b.

Kulmala, M., Mordas, G., Petäjä, T., Grönholm, T., Aalto, P. P., Vehkamäki, H., Hienola, A. I., Herrmann, E., Sipilä, M., Riipinen, I., Manninen, H., Hämeri, K., Stratmann, F., Bilde, M., Winkler, P. M., Birmili, W., and Wagner, P. E.: The Condensation Particle Counter Battery (CPCB): A new tool to investigate the activation properties of nanoparticles, J. Aerosol Sci., 38, 289304, 2007.

Kurtén, T., Noppel, M., Vehkamaki, H., Salonen, M., and Kulmala, M.: Quantum chemical studies of hydrate formation of $\mathrm{H}_{2} \mathrm{SO}_{4}$ and $\mathrm{HSO}_{4}^{-}$, Boreal Environ. Res., 12, 431-453, 2007.

Kürten, A., Rondo, L., Ehrhart, S., and Curtius, J.: Calibration of a chemical ionization mass spectrometer for the measurement of gaseous sulfuric acid, J. Phys. Chem., 116, 6375-6386, doi:10.1021/jp212123n, 2012.

Mauldin III, R. L., Eisele, F. L., Tanner, D. J., Koschiuch, E., Shetter, R., Lefer, B., Hall, S. R., Nowak, J. B., Buhr, M., Chen, G., Wang, P., and Davis, D.: Measurements of $\mathrm{OH}, \mathrm{H}_{2} \mathrm{SO}_{4}$, and 
MSA at the South Pole during ISCAT, Geophys. Res. Lett., 28, 3629-3632, 2001.

McFiggans, G., Artaxo, P., Baltensperger, U., Coe, H., Facchini, M. C., Feingold, G., Fuzzi, S., Gysel, M., Laaksonen, A., Lohmann, U., Mentel, T. F., Murphy, D. M., O’Dowd, C. D., Snider, J. R., and Weingartner, E.: The effect of physical and chemical aerosol properties on warm cloud droplet activation, Atmos. Chem. Phys., 6, 2593-2649, doi:10.5194/acp-6-2593-2006, 2006.

Merikanto, J., Spracklen, D. V., Mann, G. W., Pickering, S. J., and Carslaw, K. S.: Impact of nucleation on global CCN, Atmos. Chem. Phys., 9, 8601-8616, doi:10.5194/acp-9-8601-2009, 2009.

Metzger, A., Verheggen, B., Dommen, J., Duplissy, J., Prevot, A. S. H., Weingartner, E., Riipinen, I., Kulmala, M., Spracklen, D. V., Carslaw, K. S., and Baltensperger, U.: Evidence for the role of organics in aerosol particle formation under atmospheric conditions, P. Natl Acad. Sci., 107, 6646-6651, 2010.

Nieminen, T., Lehtinen, K. E. J., and Kulmala, M.: Sub-10 nm particle growth by vapor condensation - effects of vapor molecule size and particle thermal speed, Atmos. Chem. Phys., 10, 97739779, doi:10.5194/acp-10-9773-2010, 2010.

O'Dowd, C. D., Aalto, P., Hameri, K., Kulmala, M., and Hoffmann, T.: Aerosol formation: Atmospheric particles from organic vapours, Nature, 416, 497-498, 2002.

Paasonen, P., Sihto, S.-L., Nieminen, T., Vuollekoski, H., Riipinen, I., Plass-Dülmer, C., Berresheim, H., Birmili, W., and Kulmala, M.: Connection between new particle formation and sulphuric acid at Hohenpeissenberg (Germany) including the influence of organic compounds, Boreal Env. Res., 14, 616-629, 2009.

Paasonen, P., Nieminen, T., Asmi, E., Manninen, H. E., Petäjä, T., Plass-Dülmer, C., Flentje, H., Birmili, W., Wiedensohler, A., Hõrrak, U., Metzger, A., Hamed, A., Laaksonen, A., Facchini, M. C., Kerminen, V.-M., and Kulmala, M.: On the roles of sulphuric acid and low-volatility organic vapours in the initial steps of atmospheric new particle formation, Atmos. Chem. Phys., 10, 11223-11242, doi:10.5194/acp-10-11223-2010, 2010.

Paulsen, D., Dommen, J., Kalberer, M., Prévôt, A. S., Richter, R., Sax, M., Steinbacher, M., Weingartner, E., and Baltensperger, U.: Secondary organic aerosol formation by irradiation of 1,3,5trimethylbenzene- $\mathrm{NO}_{\mathrm{x}}-\mathrm{H}_{2} \mathrm{O}$ in a new reaction chamber for atmospheric chemistry and physics, Environ. Sci. Technol., 39, 2668-2678, 2005.

Petäjä, T., Mauldin, III, R. L., Kosciuch, E., McGrath, J., Nieminen, T., Paasonen, P., Boy, M., Adamov, A., Kotiaho, T., and Kulmala, M.: Sulfuric acid and $\mathrm{OH}$ concentrations in a boreal forest site, Atmos. Chem. Phys., 9, 7435-7448, doi:10.5194/acp9-7435-2009, 2009.

Petäjä, T., Sipilä, M., Paasonen, P., Nieminen, T., Kurtén, T., Stratmann, F., Vehkamäki, H., Berndt, T., and Kulmala, M.: Experimental observation of strongly bound dimers of sulphuric acid: application to nucleation in the atmosphere, Phys. Rev. Lett., 106, 228302, doi:10.1103/PhysRevLett.106.228302, 2011.

Pierce, J. R. and Adams, P. J.: Uncertainty in global CCN concentrations from uncertain aerosol nucleation and primary emission rates, Atmos. Chem. Phys., 9, 1339-1356, doi:10.5194/acp-91339-2009, 2009.

Pierce, J. R., Riipinen, I., Kulmala, M., Ehn, M., Petäjä, T., Junninen, H., Worsnop, D. R., and Donahue, N. M.: Quantification of the volatility of secondary organic compounds in ultrafine par- ticles during nucleation events, Atmos. Chem. Phys., 11, 90199036, doi:10.5194/acp-11-9019-2011, 2011.

Pierce, J. R., Leaitch, W. R., Liggio, J., Westervelt, D. M., Wainwright, C. D., Abbatt, J. P. D., Ahlm, L., Al-Basheer, W., Cziczo, D. J., Hayden, K. L., Lee, A. K. Y., Li, S.-M., Russell, L. M., Sjostedt, S. J., Strawbridge, K. B., Travis, M., Vlasenko, A., Wentzell, J. J. B., Wiebe, H. A., Wong, J. P. S., and Macdonald, A. M.: Nucleation and condensational growth to $\mathrm{CCN}$ sizes during a sustained pristine biogenic SOA event in a forested mountain valley, Atmos. Chem. Phys., 12, 3147-3163, doi:10.5194/acp-12-3147-2012, 2012.

Riipinen, I., Sihto, S.-L., Kulmala, M., Arnold, F., Dal Maso, M., Birmili, W., Saarnio, K., Teinilä, K., Kerminen, V.-M., Laaksonen, A., and Lehtinen, K. E. J.: Connections between atmospheric sulphuric acid and new particle formation during QUEST III-IV campaigns in Heidelberg and Hyytiälä, Atmos. Chem. Phys., 7, 1899-1914, doi:10.5194/acp-7-1899-2007, 2007.

Riipinen, I., Manninen, H. E., Yli-Juuti, T., Boy, M., Sipilä, M., Ehn, M., Junninen, H., Petäjä, T., and Kulmala, M.: Applying the Condensation Particle Counter Battery (CPCB) to study the water-affinity of freshly-formed 2-9 nm particles in boreal forest, Atmos. Chem. Phys., 9, 3317-3330, doi:10.5194/acp-9-33172009, 2009.

Riipinen, I., Pierce, J. R., Yli-Juuti, T., Nieminen, T., Häkkinen, S., Ehn, M., Junninen, H., Lehtipalo, K., Petäjä, T., Slowik, J., Chang, R., Shantz, N. C., Abbatt, J., Leaitch, W. R., Kerminen, V.-M., Worsnop, D. R., Pandis, S. N., Donahue, N. M., and Kulmala, M.: Organic condensation: a vital link connecting aerosol formation to cloud condensation nuclei $(\mathrm{CCN})$ concentrations, Atmos. Chem. Phys., 11, 3865-3878, doi:10.5194/acp-11-38652011, 2011.

Seinfeld, J. H. and Pandis, S. N.: Atmospheric Chemistry and Physics: From Air Pollution to Climate Change, 2, John Wiley \& Sons, Inc., Hoboken, NJ, 2006.

Sihto, S.-L., Kulmala, M., Kerminen, V.-M., Dal Maso, M., Petäjä, T., Riipinen, I., Korhonen, H., Arnold, F., Janson, R., Boy, M., Laaksonen, A., and Lehtinen, K. E. J.: Atmospheric sulphuric acid and aerosol formation: implications from atmospheric measurements for nucleation and early growth mechanisms, Atmos. Chem. Phys., 6, 4079-4091, doi:10.5194/acp-6-4079-2006, 2006.

Sipilä, M., Berndt, T., Petäjä, T., Brus, D., Vanhanen, J., Stratmann, F., Patokoski, J., Mauldin III, R. L., Hyvärinen, A.-P., Lihavainen, H., and Kulmala, M.: The Role of sulfuric acid in atmospheric nucleation, Science, 327, 1243-1246, 2010.

Smith, J. N., Dunn, M. J., VanReken, T. M., Iida, K., Stolzenburg, M. R., McMurry, P. H., and Huey, M. R.: Chemical composition of atmospheric nanoparticles formed from nucleation in Tecamac, Mexico: Evidence for an important role for organic species in nanoparticle growth, Geophys. Res. Lett., 35, L04808, doi:10.1029/2007GL032523, 2008.

Smith, J. N., Barsanti, K. C., Friedli, H. R., Ehn, M., Kulmala, M., Collins, D. R., Scheckman, J. H., Williams, B. J., and McMurry, P. H.: Observations of aminium salts in atmospheric nanoparticles and possible climatic implications, P. Natl Acad. Sci. USA, 107, 6634-6639, 2010.

Spracklen, D., Carslaw, K., Kulmala, M., Kerminen, V.-M., Sihto, S.-L., Riipinen, I., Merikanto, J., Mann, G., Chipperfield, M., Wiedensohler, A., Birmili, W., and Lihavainen, H.: 
Contribution of particle formation to global cloud condensation nuclei concentrations, Geophys. Res. Lett., 35, L06808, doi:10.1029/2007GL033038, 2008.

Stolzenburg, M. and McMurry, P.: An ultrafine aerosol condensation nucleus counter, Aerosol Sci. Technol., 14, 48-65, 1991.

Twomey, S.: The influence of pollution on the shortwave albedo of clouds, J. Atmos. Sci., 34, 1149-1152, 1977.

Vanhanen, J., Mikkilä, J., Lehtipalo, K., Sipilä, M., Manninen, H.E., Siivola, E., Petäjä, T., and Kulmala, M.: Particle size magnifier for nano-CN detection, Aerosol Sci. Technol., 45, 533-542, 2011.

Vuollekoski, H., Nieminen, T., Paasonen, P., Sihto, S.-L., Boy, M., Manninen, H. E., Lehtinen, K. E. J., Kerminen, V.-M., and Kulmala, M.: Atmospheric nucleation and initial steps of particle growth: Numerical comparison of different theories and hypotheses, Atmos. Res., 98, 229-236, 2010.

Wang, L., Khalizov, A. F., Zheng, J., Xu, W., Ma, Y., Lal, V., and Zhang, R.: Atmospheric nanoparticles formed from heterogeneous reactions of organics, Nature Geosci., 3, 238-242, 2010.

Wang, S. C. and Flagan, R. C.: Scanning Electrical Mobility Spectrometer, Aerosol Sci. Technol., 13, 230-240, 1990.
Weber, R. J., Marti, J. J., McMurry, P. H., Eisele, F. L., Tanner, D. J., and Jefferson, A.: Measured atmospheric new particle formation rates: Implications for nucleation mechanisms, Chem. Eng. Commun., 151, 53-64, 1996.

Wehner, B., Petäjä, T., Boy, M., Engler, C., Birmili, W., Tuch, T., Wiedensohler, A., and Kulmala, M.: The contribution of sulfuric acid and non-volatile compounds on the growth of freshly formed atmospheric aerosols, Geophys. Res. Lett., 32, L17810, doi:10.1029/2005GL023827, 2005.

Yli-Juuti, T., Nieminen, T., Hirsikko, A., Aalto, P. P., Asmi, E., Hõrrak, U., Manninen, H. E., Patokoski, J., Dal Maso, M., Petäjä, T., Rinne, J., Kulmala, M., and Riipinen, I.: Growth rates of nucleation mode particles in Hyytiälä during 20032009: variation with particle size, season, data analysis method and ambient conditions, Atmos. Chem. Phys., 11, 12865-12886, doi:10.5194/acp-11-12865-2011, 2011.

Zhang, R., Wang, L., Khalizov, A. F., Zhao, J., Zheng, J., McGraw, R. L., and Molina, L. T.: Formation of nano-sized particles of blue haze enhanced by anthropogenic pollution, P. Natl. Acad. Sci., 106, 17650-17654, 2009. 